\title{
Characterization of shot peened 2024-T351 aluminum alloy
}

\begin{abstract}
Specimens of 2024-T351 aluminium alloy under different three shot peening intensities were studied. The modifications of the surface layers of the shot peened specimens were investigated through microhardness, surface microstructure and residual stress relaxation after the first and second load cycles under two cyclic loads. No significant changes in microstructure after the three shot peeing intensities were observed with respect to untreated specimens. Rapid residual stress relaxation was observed in specimens after the first cycle. Relaxation of residual stresses occurred within first loading cycles were increased with increasing loading stress amplitude and due to quasi-static relaxation effects.
\end{abstract}

Keyword: 2024-T351 aluminum alloy; Residual stress relaxation; Shot peening 